Article

\title{
Biennial Mowing Maintains the Biomass and Functional Diversity of Semi-Arid Grassland
}

\author{
Tianqi Zhao ${ }^{1,2}$, Feng Zhang ${ }^{1}$, Rongzhen Suo ${ }^{1,3}$, Chen Gu ${ }^{1,2}$, Daling Chen ${ }^{1}$, Tony Yang ${ }^{2} \mathbb{D}$ and \\ Mengli Zhao ${ }^{1, *}$ \\ 1 College of Grassland, Resources and Environment, Inner Mongolia Agricultural University, Hohhot, \\ Inner Mongolia 010018, China; tianqi.zhao@canada.ca (T.Z.); andrew.fengzhang@gmail.com (F.Z.); \\ rongzhen.suo@canada.ca (R.S.); guchen0706@emails.imau.edu.cn (C.G.); darling81315@126.com (D.C.) \\ 2 Agriculture and Agri-Food Canada, Swift Current Research and Development Centre, \\ Swift Current, SK S9H 3X2, Canada; tony.yang@canada.ca \\ 3 Agriculture and Agri-Food Canada, Morden Research and Development Centre, \\ Morden, MB R6M 1Y5, Canada \\ * Correspondence: nmgmlzh@126.com
}

Received: 25 December 2019; Accepted: 5 February 2020; Published: 18 February 2020

\begin{abstract}
Understanding the functional diversity relationship between biomass and plants is a key issue in biodiversity-ecosystem functionality and the utility of grassland. We conducted a five-year mowing experiment to examine the effects of the mowing frequency on biomass, plant species, and functional diversity of a natural plant community in a semiarid region of Inner Mongolia. A secondary objective was to test whether unmowed refuge areas within plots would mitigate the disturbance effect of mowing. The result showed that mowing disturbance reduced biomass by the greatest amount with mowing once every year (M1) and the least with M2. The biomass composition of M2 consisted of a greater mass of perennial species than in the other mowing treatments but was equivalent to the control (CK). However, mowing disturbances increased the plant species richness and M2 had the largest number of species. The community-weighted means (CWM) indices indicated that M2 produced the least detrimental effects on the grassland. Retaining unmowed refuge areas appeared to be ineffective in promoting beneficial community traits under M1 mowing regimes. Based on our results, we recommend that the semi-arid grassland be mowed every other year in order to optimize sustainable production.
\end{abstract}

Keywords: natural grassland; biodiversity; cutting; community-weighted mean; survival strategy

\section{Introduction}

Mowing is an important method for harvesting forage worldwide [1]. Due to the environmental degradation that started in the mid 1980s, the plant biomass and functional diversity of many grassland communities have declined significantly [2,3]. Proper mowing can mitigate the effects of overgrazing [1]. Traditionally, mowing semi-arid grasslands is done once a year. However, this frequency has been questioned because of its deleterious ecological effects [4] defined by the link between biomass and functional diversity [5]. This is especially true for grasslands located in the Inner Mongolia Autonomous Region in northern China, which have been heavily overgrazed, reducing not only their productivity but also many of their eco-functions, such as hydrology [6], biodiversity [7], and the carbon cycle [8,9]. With the accelerated loss of biodiversity, there is an urgent need to assess grassland use impacts, which can be done by examining their functional traits [10].

Compared with the semi-natural grassland mowing regimes and the corresponding conservation management in Europe [11], mowing natural grassland is an important management practice for 
preparing winter feed for livestock production in the semi-arid regions in northern China, Mongolia, and east Russia [12]. The Typical Steppe is the most widely distributed type of native grassland suitable for mowing in the pastoral regions in Inner Mongolia [13]. Rotational mowing dates and frequencies [14] have a small effect on the reproduction of grassland community plants and can avoid the excessive use of grassland resources [15]. From this perspective, mowing may be an effective grassland management practice and substitute for grazing for semi-arid natural grasslands $[1,3,8]$. Moreover, mowing has also been found to enhance the growth, and thus the relative abundance, of $\mathrm{C} 4$ species in natural grassland [16], producing higher light saturation point [17], photosynthetic rate [18], and water use efficiency [19].

An appropriate mowing regime can maintain high plant species richness [15] and reduce competition [20] by inhibiting tall plant species [3], thereby allowing short species to persist. However, mowing disturbances can also have negative impacts on species richness and plant traits that alter the community's structure and function [2], including its productivity [21]. Therefore, Roel et al. [22] suggested keeping an unmowed refuge zone within the grassland to increase species diversity in grasslands. Based on theoretical and empirical evidence, Doležal et al. [23] argued that seasonal mowing shifts community composition, which may reduce competitive interactions and promote the coexistence of dominant and subordinate species.

Plant functional traits not only determine how plants respond to environmental factors [24], but also represent important indicators of ecological strategies that affect the attributes of plant communities and ecosystems. However, knowledge of the effects of overuse on grassland plant traits and plant community stability in the context of farm management remains scarce. Therefore, in this study, we focus on the responses of functional traits to mowing $[1,16]$.

Varying the functional traits of plant communities along an environmental disturbance gradient is expected to reflect changes in the optimal values. Because the variation of performance around an optimal value translates into a variation in species abundances related to trait values, the mean values of the traits in communities known as the community-weighted mean (CWM) are used to reflect the local optimal trait values [24].

Previous research [25] indicated that leaf traits were primarily selected in the best models for predicting biomass. The CWM of leaf area is the most important predictor [26] with an expected positive relationship [25]. Others [27] assessed the influence of functional plant trait composition shifts in community-weighted trait distributions. The majority of plants in the grasslands of northern China tended to become miniaturized in response to long-term defoliation [3]. Although plant height is considered to be the most important functional trait for predicting community productivity [28], taller plants had leaves with smaller specific leaf areas. Nevertheless, short and unpalatable species increased more often with grazing disturbances, while the proportion of short species with large leaf areas increased with mowing disturbances.

Changes in grassland biomass are an important topic in both mowing [15] and grazing research [8]. Studies have shown that complementary effects occur when communities exhibit higher functional trait differences that increase the optimal use of resources and increase productivity [16,25]. Generally, studies have shown that there is a close relationship between biomass and CWM trait values [21]. However, some researchers have shown that grassland defoliation with either grazing or mowing leads to a decrease in productivity [21,29]. Studies on European mountain grasslands have shown that mowing reduces grassland yields and the need to adapt mowing management during drought years [1]. This result clearly supports the "biomass-ratio hypothesis" [5], which states that ecosystem properties are driven by the characteristics of dominant species in the community. Additionally, it has been shown that management with intermediate disturbance regimes will maximize biomass yields, while the influence of climatic variables on biomass is less important [15]. A recent study showed that aboveground plant biomass decreased significantly in response to long-term defoliation by mowing under field conditions [3]. Other researchers report that functional dominance is the best predictor of aboveground biomass in the grassland community $[16,25,28]$. 
Clarification via ecological research is needed to determine whether grassland plant traits would respond to over-exploitation. Moreover, the knowledge of changes in natural semi-arid grassland community traits after mowing is very limited. These are not only fundamental ecological indicator questions, but also have important implications for biodiversity conservation and optimizing mowing regimes. Therefore, in this study, we intend to address three specific questions: (1) Compared with other mowing regimes, does biennial mowing enhance the conservation of semi-arid grassland? (2) How do plant species and functional diversity change under different mowing management? (3) In particular, what is the relationship between plant traits and biomass under different mowing regimes?

\section{Materials and Methods}

\subsection{Study Areas}

This study was performed in the Xilingol Typical Steppe $\left(116^{\circ} 14^{\prime} 22^{\prime \prime}\right.$ E, $\left.44^{\circ} 12^{\prime} 42^{\prime \prime} \mathrm{N}\right)$, a part of the Eurasian Steppe [2]. This area is located in a temperate continental semiarid region characterized by significant inter- and intra-annual variability [17]. The mean annual average temperature is $0.4^{\circ} \mathrm{C}$, with the highest monthly temperature in July $\left(20.6{ }^{\circ} \mathrm{C}\right)$ and the lowest mean monthly temperature in January $\left(-21.7^{\circ} \mathrm{C}\right)$. The local elevation is $1150 \mathrm{~m} \mathrm{[13]}$. The semi-arid continental climate is characterized by mean annual precipitation ranging from 104 to $411 \mathrm{~mm}$. Typically, the maximum precipitation coincides with the highest temperature during the plant growing season (June, July, and August). The low precipitation amounts during winter and the strong wind in this region usually result in a shallow but often unevenly distributed snow cover [30]. For dominant species like Stipa grandis and Leymus chinensis, the 180-day growing season lasts from mid-April to mid-October. The major soil type in this region is Typical Chestnut [2]. Currently, the grassland is grazed by sheep and goats, although some areas are mowed once a year at the end of the growing season [17].

\subsection{Experiment Design}

Our experiment was initiated in September 2014 on natural grasslands in the Xilingol Typical Steppe, which has traditionally been used as rangeland for both livestock grazing and mowing [31]. To exclude the effects of grazing on plant traits and productivity, the experimental area was established in a fenced grassland that had not been grazed for at least 40 years [32]. To ensure that mowing was the only anthropogenic influence on the grassland plants, we selected sites with little or no slope and spatially homogenous vegetation.

We examined the effects of five mowing treatments with three replicates in a completely randomized experimental design. The mowing treatments were: (1) non-mown plots (CK: $30 \mathrm{~m} \times 50 \mathrm{~m}$ ); (2) mowing once a year (M1: $30 \mathrm{~m} \times 50 \mathrm{~m}$ ); (3) biennial mowing (M2: $30 \mathrm{~m} \times 50 \mathrm{~m}$ ); 4) mowing once a year but leaving a 10\% unmowed refuge areas (R10: cut part $30 \mathrm{~m} \times 50 \mathrm{~m}+$ uncut part $30 \mathrm{~m} \times 5 \mathrm{~m}$ ); and (5) mowing once a year but leaving $20 \%$ as an unmowed grass refuge area (R20: cut part $30 \mathrm{~m} \times 50 \mathrm{~m}+$ uncut part $30 \mathrm{~m} \times 10 \mathrm{~m}$ ). The unmowed refuge area was always on the right of the cut area within each plot. Vegetation sampling was conducted only in the mowed part. Mowing was done in mid-August every year.

\subsection{Sample Collection}

The above-ground biomass and plant traits of this study were sampled on 15 August 2018 in 3 $1 \mathrm{~m} \times 1 \mathrm{~m}$ quadrats located randomly in each of the 15 plots. The aboveground biomass of all plants in each quadrat was harvested at ground level. We recorded the occurrence of species that were found and created a list of species present in the experimental area. The mowing treatments were applied at a height of $8 \mathrm{~cm}$ above ground level and the cut biomass was removed. Each treatment plot had a $5 \mathrm{~m}$ buffer.

We measured four plant traits that varied in response to community disturbances as well as their functional links to plant growth, development, and resource acquisition. The traits were plant height 
$(\mathrm{H})$, leaf length (LL), number of leaves (TNL), and specific leaf area (SLA, the ratio of leaf area to leaf dry mass). Plant height was measured for three individual plants of each species found in the quadrats, and the average values were determined. The plants selected demonstrated good growth, intact leaves, fully expanded leaves, and showed no evidence of pests or diseases. The leaf area was measured using a laser leaf area meter (CI-203, CID Corporation, China, Beijing). We measured the total aboveground plant biomass and classified the plants into annual and perennial plants. All samples were dried at $80^{\circ} \mathrm{C}$ for $48 \mathrm{~h}$ and weighed.

\subsection{Statistical Analysis}

To clearly understand the changes in the community structure caused by mowing disturbances, we calculated three species diversity indices (Table S1). To determine the functional responses driving community composition across the mowing regimes, we calculated the CWM, which was determined by multiplying the trait value of each species by its relative dry weight as measured by the abundance in each plot. This metric represents the expected functional trait value of a specific community [26]. $C W M_{x}=\sum_{i=1}^{s} p_{i} t_{i}$, where CWM $x$ is the CWM for trait $x, s$ is the number of species in the community, $p_{i}$ is the relative abundance of the $i$ species in the community, and $t_{i}$ is the trait value for the $i$ th species.

In order to establish the relationships of the four plant functional traits, a principal component analysis (PCA) was carried out. The variables were normalized prior to performing this analysis and their centroids were determined by subtracting their values from their mean, which was adjusted for the different units used. In the analysis results, the relative load on the component indicates the importance of the features in a particular component.

To summarize the effect of mowing on the community biomass, we calculated the "Mowing effect" [33], which is as follows:

Mowing effect $=$ the ratio of the biomass under mowing to the biomass of the control. A value of $>1$ means that mowing increased the biomass, and a value $<1$ indicates that mowing decreased the biomass. The larger the value, the better the grassland recovery.

We used linear models to fit the relationships of mowing effects with the plant functional traits $\left(C W M_{H}, C W M_{T N L}, C W M_{L L}\right.$, and $\left.C W M_{S L A}\right)$. Significant differences in biomass, species number (total, annual, and perennial plants), plant functional traits, and mowing effect between the five mowing treatments were assessed by one-way analysis of variance (ANOVA) procedures. The statistical significance was set at $p<0.05$. Multiple comparisons of the means were based on a Duncan's post hoc test. Data were expressed as the mean \pm standard error (SE). All analyses were performed with the $R$ software (R Development Core Team, version 3.5.1, 2018).

\section{Results}

Mowing once a year resulted in a significant decrease of total plant biomass compared with M2 and CK (Figure 1, Total). For the perennial plant, the biomass under M2 was much higher than that under M1 and was not significantly different compared to CK. Both R10 and R20 treatments significantly reduced the perennial plant biomass compared with the CK (Figure. 1, Perennial). For the annual plant, only the M1 treatment significantly reduced the biomass yield (Figure 1, Annual).

The mowing practices resulted in an increased number of plant species (Table 1, Figure 2) compared with CK. In particular, the number of plant species under M2 treatment was the highest at 22 (Table 1). For the three species diversity indices (Shannon-Weaver, evenness, and dominance), M2 also showed the highest average scores among all mowing treatments $(p>0.05)$ which had significantly $(p>0.05)$ higher scores than CK (Figure 2). 


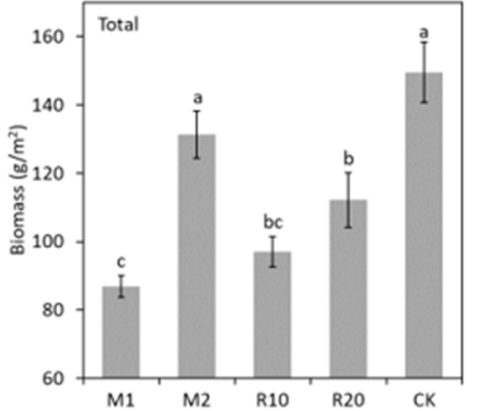

(a)

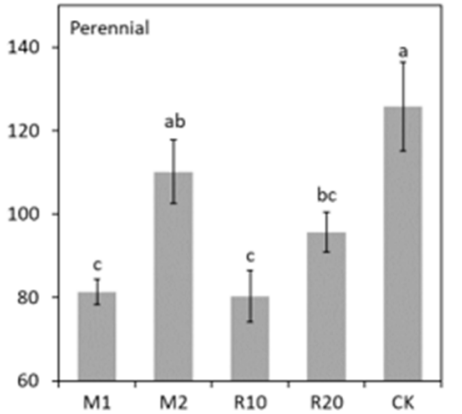

(b)

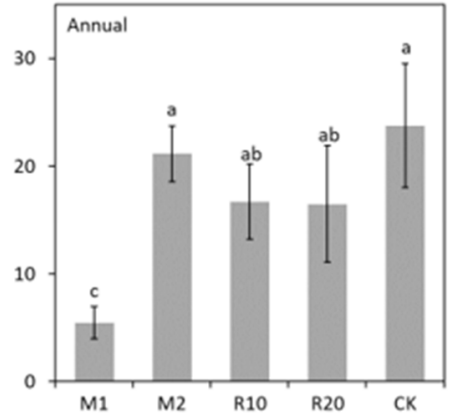

(c)

Figure 1. The biomasses of community plants (total, perennial, and annual plants) under different mowing methods ((a) total, (b) perennial, and (c) annual plants). Different small letters indicate significant differences among the treatments according to the least significant difference tests at $p<$ $0.05, \mathrm{n}=45$. Abbreviations: non-mown plots (CK); mowing once a year (M1); biennial mowing (M2); mowing once a year while leaving $10 \%$ unmowed refuge areas (R10); mowing once a year while leaving $20 \%$ unmowed refuge areas (R20). The same is shown below.

Table 1. The occurrence of plant species under different mowing treatments.

\begin{tabular}{|c|c|c|c|c|c|c|c|}
\hline Number & Latin Name & $\begin{array}{l}\text { Plants } \\
\text { Type }\end{array}$ & M1 & M2 & R10 & R20 & CK \\
\hline 1 & Stipa grandis & \multirow{26}{*}{ Perennial } & + & + & + & + & + \\
\hline 2 & Cleistogenes squarrosa & & + & + & + & + & + \\
\hline 3 & Agropyron michnoi & & Absent & + & absent & + & + \\
\hline 4 & Leymus chinensis & & + & + & + & + & + \\
\hline 5 & Anemarrhena asphodeloides & & + & + & + & + & + \\
\hline 6 & Allium tenuissimum & & Absent & + & + & absent & + \\
\hline 7 & Thalictrum petaloideum & & Absent & + & + & + & + \\
\hline 8 & Allium bidentatum & & + & + & + & + & + \\
\hline 9 & Allium ramosum & & Absent & absent & absent & + & absent \\
\hline 10 & Astragalus galactites & & Absent & + & absent & + & absent \\
\hline 11 & Convolvulus ammannii & & + & absent & + & absent & absent \\
\hline 12 & Scutellaria viscidula & & Absent & + & absent & absent & absent \\
\hline 13 & Carex korshinskyi & & + & + & absent & absent & absent \\
\hline 14 & Caragana microphylla & & Absent & + & absent & + & + \\
\hline 15 & Androsace umbellata & & + & absent & absent & + & absent \\
\hline 16 & Parthenocissus tricuspidata & & + & + & + & absent & absent \\
\hline 17 & Gueldenstaedtia & & + & absent & + & absent & absent \\
\hline 18 & Ephedra sinica & & Absent & absent & + & absent & absent \\
\hline 19 & Artemisia frigida & & + & absent & absent & absent & absent \\
\hline 20 & Cymbaria dahurica & & Absent & + & absent & + & + \\
\hline 21 & Gentiana scabra & & Absent & + & absent & absent & absent \\
\hline 22 & Polygala tenuifolia & & + & absent & absent & absent & + \\
\hline 23 & Oxytropis myriophylla & & + & absent & absent & + & absent \\
\hline 24 & Ruta graveolens & & + & absent & + & absent & absent \\
\hline 25 & Euphorbia esula & & Absent & + & absent & absent & + \\
\hline 26 & Asparagus cochinchinensis & & Absent & + & absent & absent & absent \\
\hline 1 & Corispermum hyssopifolium & \multirow{5}{*}{ Annual } & + & + & + & + & + \\
\hline 2 & Chenopodium aristatum & & + & + & + & + & + \\
\hline 3 & Salsola collina & & + & + & + & + & + \\
\hline 4 & Oxybasis glauca & & + & + & + & + & absent \\
\hline 5 & Chenopodium acuminatum & & + & + & + & + & absent \\
\hline
\end{tabular}

Note: "+" represents the species identified in the community; "absent" represents species not identified in the community. 


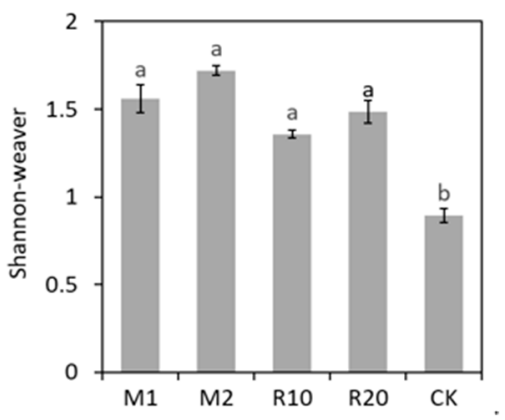

(a)

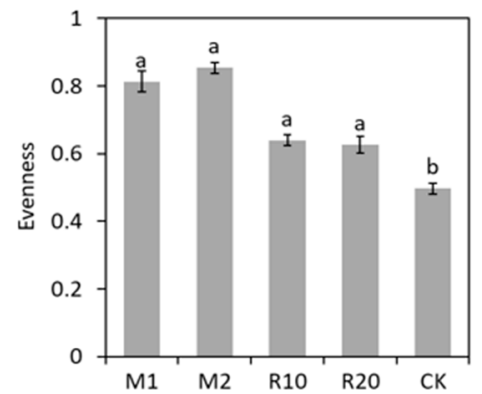

(b)

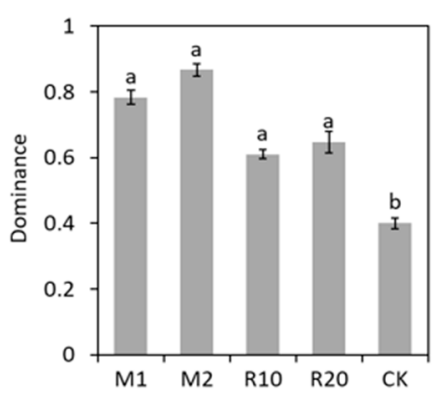

(c)

Figure 2. Community species diversity indices (Shannon-Weaver, evenness, and dominance) under different mowing regimes ((a) Shannon-Weaver, (b) evenness, and (c) dominance. Different small letters indicate significant differences among the treatments according to a least significant difference test at $p<0.05, \mathrm{n}=45$.

The two leading axes of the PCA gathering the 45 quadrats' CWM values accounted for $86.7 \%$ of the inertia (Figure 3). Along the first axis, $C W M_{H}, C W M_{T N L}, C W M_{L L}$, and $C W M_{S L A}$ contents were positively related. Among these parameters, only $C W M_{S L A}$ showed a low contribution to the model.

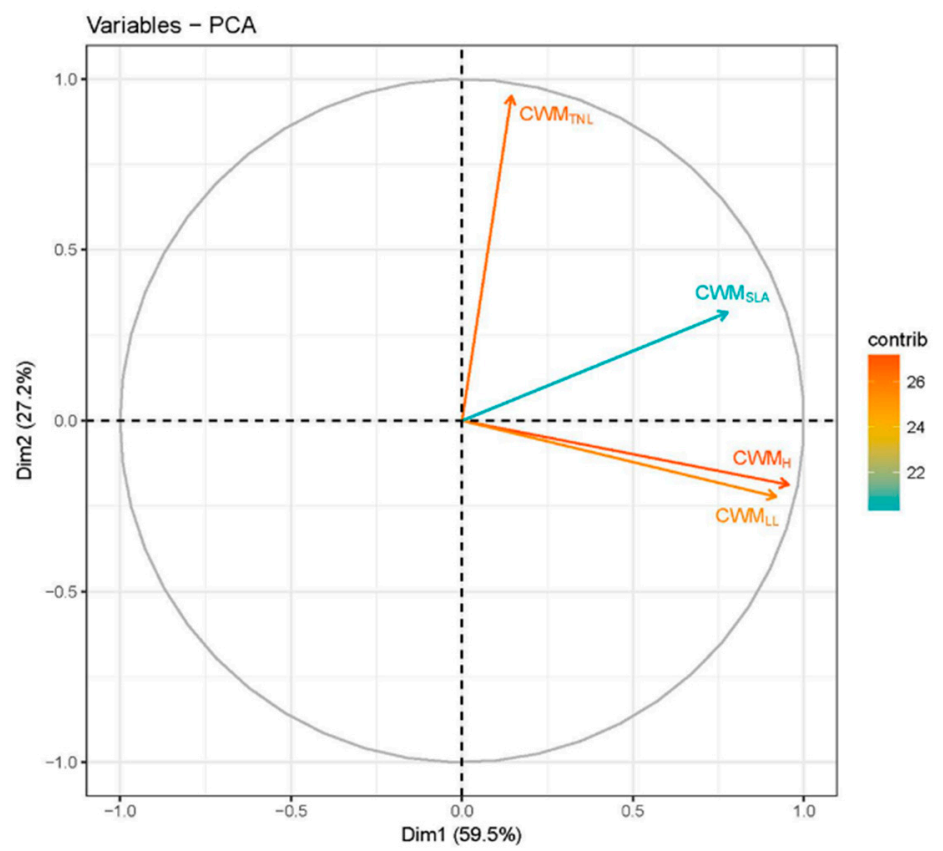

Figure 3. Principal component analysis (PCA) of the CWM values of the four functional plant traits: contrib: factor contribution rate; the blue color indicates a low contribution rate, while the red color indicates a high contribution rate, $\mathrm{n}=45$. Abbreviations: four plant traits: plant height $\left(C W M_{H}\right)$, leaf length $\left(C W M_{L L}\right)$, number of leaves $\left(C W M_{T N L}\right)$, and special leaf area $\left(C W M_{S L A}\right)$. The same is shown below.

For each CWM index, the values for M2 were the highest among the mowing treatments and equivalent to that of the CK (Figure 4). The mean CWM values for M1 were consistently the lowest (Figure 4) among the treatments (Figure 4). We observed a positive $(p<0.01)$ relationship between the mowing effect and the values of $\mathrm{CWM}_{\mathrm{H}}, \mathrm{CWM}_{\mathrm{TNL}}, \mathrm{CWM}_{\mathrm{LL}}$, and CWM $\mathrm{CLA}$ (Figure 5). 

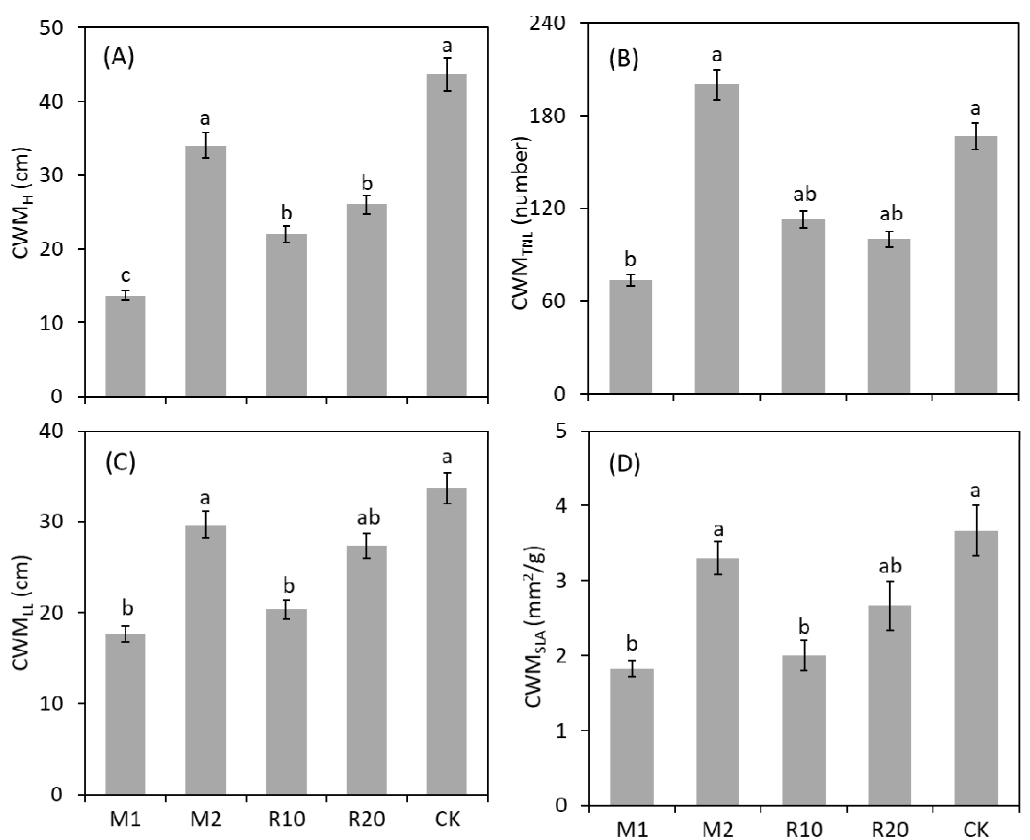

Figure 4. The CWM values of different mowing methods. Different small letters indicate significant differences among the treatments according to a least significant difference test at $p<0.05, \mathrm{n}=45$. (A-D) indicates four plant traits $\left((\mathbf{A}) \mathrm{CWM}_{\mathrm{H}},(\mathbf{B}) \mathrm{CWM}_{\mathrm{TNL}},(\mathbf{C}) \mathrm{CWM}_{\mathrm{LL}}\right.$ and (D) CWM $\left.\mathrm{CLA}\right)$.

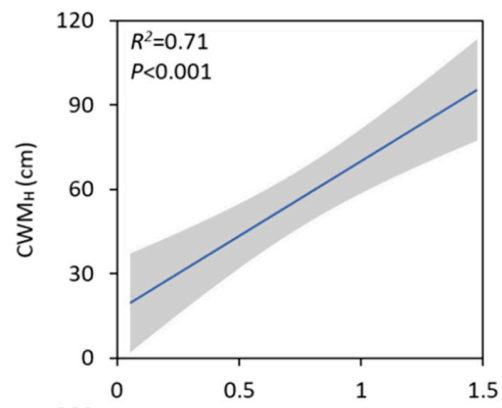

(A)

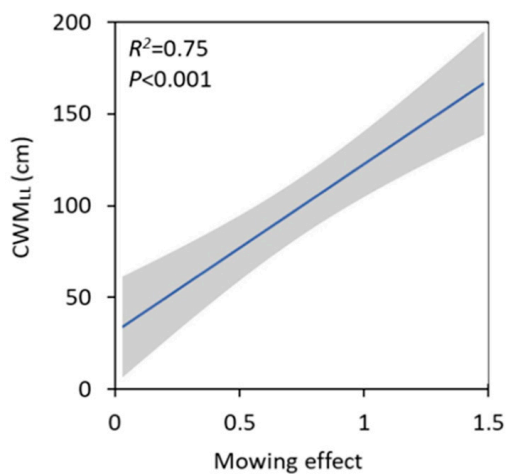

(C)

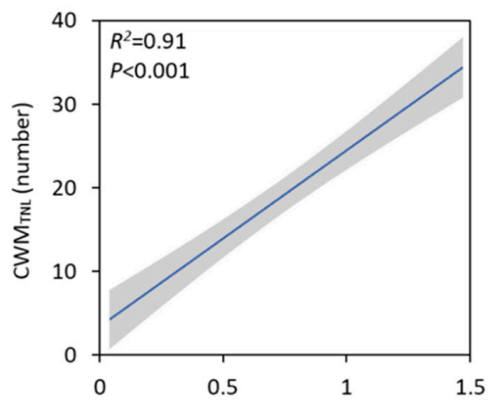

(B)

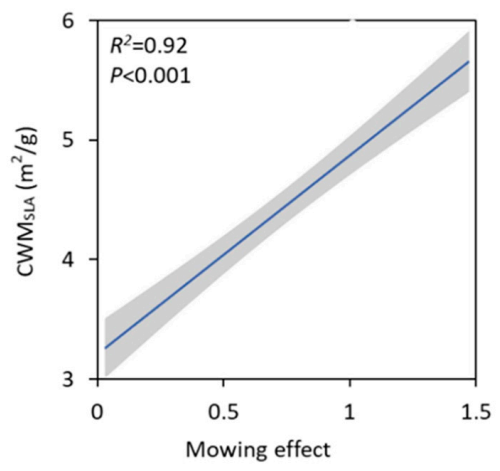

(D)

Figure 5. Variations of mowing effects with CWM ((A) $\mathrm{CWM}_{\mathrm{H}},(\mathbf{B}) \mathrm{CWM}_{\mathrm{TNL}},(\mathbf{C}) \mathrm{CWM}_{\mathrm{LL}}$ and (D) $\mathrm{CWM}_{\text {SLA }}$ ) values by linear models, $\mathrm{n}=36$. 


\section{Discussion}

Mowing practices increased the number of species compared with the control, and all mowing can increase species diversity within five years. Different mowing frequencies changed the composition of plant community and reduced competitive interactions, thus promoting the coexistence of dominant and subordinate species [23]. The effects of mowing frequency on species diversity were not affected between mowing treatments, possibly because the annual species increased with mowing once a year, which offset the losses of perennial species.

More perennial grasses appeared under mowing disturbances which may be due to better growing conditions for subordinate species, such as Carex korshinskyi and Astragalus galactites, while mowing limited the growth of tall species, such as Stipa grandis and Leymus chinensis. This supports the "intermediate disturbance" hypothesis [34]. However, annual mowing changed the composition of the plant community as we found some taller perennial plants such as Allium tenuissimum and Allium ramosum disappeared, while some rare species with low plant heights, such as Oxytropis myriophylla and Convolvulus ammannii, appeared. The less frequent disturbances over a four-year period clearly demonstrated the importance of mowing frequency as a determining factor in affecting community diversity [14]. Another study showed that delaying mowing could deliver substantial benefits for functional biodiversity, including more sustainable production [4].

Harvesting biennially is a method that enhances the functional traits and productivity of the plants. This is due to $\mathrm{H}$ and SLA allowing for the efficient capture of resources at the cost of being susceptible to harvest, with low $\mathrm{H}$ and SLA achieving better resource retention and higher persistence. Therefore, the functional traits found with less frequent mowing were similar to those of the control but were higher than those with an annual mowing disturbance.

At the community scale, the leaves in M2 were more plentiful in number than those in the control plots but fewer in the M1 treatment, suggesting a clear decrease in plant growth and an increased leaf toughness with greater mowing disturbances. These changes were accompanied by shorter leaf lengths, which could indicate a reduction in the transpiring leaf surface, a mechanism to reduce the water requirements observed in the species from semi-arid grassland dry habitats that experience mowing every year [1]. The principal component analysis showed a high degree of explanatory power for the four functional traits and all were positively correlated.

The mowing methods affected plant traits through species turnover and intraspecific influence on plant height and biomass [35] and supported our hypothesis that reducing leaf area is a survival strategy in response to intense disturbance. Therefore, when the leaf area is reduced, the whole plant size tends to be miniaturized [3]. The most obvious decrease was found in the heights of the plants mowed annually, which were significantly shorter than those under other treatments.

Mowing disturbances can lead to retrogressions in the community, and in our study, annual mowing did not provide sufficient time for the community to recover [36]. Plant height and biomass increase with recovery. This is not surprising given the typical correlation between these two traits, which both have a key role to play in resource acquisition and competitive ability. Gaberščik et al. found that species diversity increased along a hydrological gradient [37]. However, other studies have not found a clear relationship between productivity and richness within sites, within regions, or across the globe [38]. In our study, we observed that all functional traits increased with the mowing effect, which indicated that more biomass is available, thus supporting our hypothesis that biennial mowing can lead to higher plant functional traits.

The refuge areas adjacent to the annually mowed areas appeared to mitigate the effects of mowing on species richness, but not significantly. This lack of effect is possibly due to two reasons. First, there were no significant changes in the species composition of the unmowed refuge area within a short period of time (five years). Secondly, our mowing time was situated in mid-August each year when the plants in the grassland were completely matured and had dropped their seeds. Therefore, the plants in the unmowed area may not have a significant impact on species composition in the mowed areas. 
These mowing methods were designed because of agri-environment schemes [11] that compensate farmers financially for any loss of income associated with measures that aim to benefit the environment or biodiversity by leaving an unmowed refuge areas [22] or limiting cutting frequency [14,15]. Retaining unmowed refuge areas may enhance moisture conditions on the mowed portions by trapping snow, which may provide a source of germplasm and promote species richness among orthopterans [4]. Thus, we believe these refuge areas could increase species richness over a longer time, which could produce more potential benefits for grassland restoration. However, these potential benefits were not clearly evident in our study.

Mowing management can be used to change the biomass of the community. Our results indicate that intensive grassland use, such as mowing every year in a semi-arid grassland, causes a decline in biomass, but mowing every other year had no effect. Baoyin et al. [12] suggested that the best practice for haymaking from L. chinensis grassland in Inner Mongolia should be based on the practice of "mowing once a year" in high-production years but with grazing in low-production years. Furthermore, light grazing early in the season may increase hay quality when mowed in the autumn if the grassland grows well early in the season in high-production years. In contrast to the L. chinensis grassland, which is more mesic than the Typical Steppe of our experimental site, mowing once a year will make the grassland degrade more rapidly [18], and less frequent mowing is a more sustainable management practice [39]. Biennial mowing provides sufficient opportunity for the growth and recovery time for annual plants, making their biomass significantly higher than that of other mowing treatments and accounting for a large proportion of total biomass. Therefore, we believe that biennial mowing in anthropogenically stressed grasslands can enhance species and functional diversity.

\section{Conclusions}

Mowing disturbances increased species richness and had no effect on the productivity of the semi-arid grassland community. Mowing every other year can reduce the competitive interactions among plants and promote the coexistence of dominant and subordinate species. Mowing annually while leaving a refuge area can provide a source of germplasm, but this benefit was not expressed over a five-year period. An optimal sustainable forage yield can be achieved by mowing every other year. The findings from this study will be useful for developing a more mechanistic understanding of mowing management in the development of sustainable production in semi-arid grasslands.

Supplementary Materials: The following are available online at http:/www.mdpi.com/2071-1050/12/4/1507/s1, Table S1: Species diversity index calculations.

Author Contributions: T.Z. and M.Z. conceived and performed the research; F.Z. and R.S. mainly contributed to the investigation and data curation; C.G., T.Y., and D.C. made suggestions for the revision of the paper; T.Z. wrote the paper. All authors have read and agreed to the published version of the manuscript.

Funding: This research was supported by the National Natural Science Foundation of China (31861143001). Appreciation is expressed for the support of equipment by the technical staff of the Key Laboratory of Grassland Resources, the Ministry of Education, College of grassland, Resources and Environment, Inner Mongolia Agricultural University.

Conflicts of Interest: The authors declare no conflict of interest.

\section{References}

1. Deléglise, C.; Meisser, M.; Mosimann, E.; Spiegelberger, T.; Signarbieux, C.; Jeangros, B. Drought-induced shifts in plants traits, yields and nutritive value under realistic grazing and mowing managements in a mountain grassland. Agr. Ecosyst. Environ. 2015, 213, 94-104. [CrossRef]

2. Bai, Y.; Wu, J.; Clark, C.M.; Pan, Q.; Zhang, L.; Chen, S. Grazing alters ecosystem functioning and C:N:P stoichiometry of grasslands along a regional precipitation gradient. J. Appl. Ecol. 2012, 49, 1204-1215. [CrossRef] 
3. Li, X.; Wu, Z.; Liu, Z.; Hou, X.; Badgery, W.; Guo, H. Contrasting Effects of Long-Term Grazing and Clipping on Plant Morphological Plasticity: Evidence from a Rhizomatous Grass. PLoS ONE 2015, 10, 10. [CrossRef] [PubMed]

4. Buri, P.; Arlettaz, R.; Humbert, J.Y. Delaying mowing and leaving uncut refuges boosts orthopterans in extensively managed meadows: Evidence drawn from field-scale experimentation. Agr. Ecosyst. Environ. 2013, 181, 22-30. [CrossRef]

5. Grime, J. Benefits of plant diversity to ecosystems: Immediate, filter and founder effects. J. Ecol. 1998, 86, 902-910. [CrossRef]

6. Wen, Z.; Zheng, H.; Smith, J.R.; Zhao, H.; Liu, L.; Ouyang, Z. Functional diversity overrides community-weighted mean traits in linking land-use intensity to hydrological ecosystem services. Sci. Total Environ. 2019, 682, 583-590. [CrossRef] [PubMed]

7. Mauchamp, L.; Mouly, A.; Badot, P.M.; Gillet, F. Impact of management type and intensity on multiple facets of grassland biodiversity in the F rench J ura M ountains. Appl. Veg. Sci. 2014, 17, 645-657. [CrossRef]

8. Han, G.; Hao, X.; Zhao, M.; Wang, M.; Ellert, B.H.; Willms, W. Effect of grazing intensity on carbon and nitrogen in soil and vegetation in a meadow steppe in Inner Mongolia. Agr. Ecosyst. Environ. 2008, 125, 21-32. [CrossRef]

9. Qu, L.; Chen, J.; Dong, G.; Shao, C. Heavy mowing enhances the effects of heat waves on grassland carbon and water fluxes. Sci. Total Environ. 2018, 627, 561-570. [CrossRef]

10. Wellstein, C.; Schröder, B.; Reineking, B.; Zimmermann, N.E. Understanding species and community response to environmental change-A functional trait perspective. Agr. Ecosyst. Environ. 2011, 145, 1-4. [CrossRef]

11. Kleijn, D.; Sutherland, W.J. How effective are European agri-environment schemes in conserving and promoting biodiversity? J. Appl. Ecol. 2003, 40, 947-969. [CrossRef]

12. Baoyin, T.; Li, F.Y.; Bao, Q.; Minggagud, H.; Zhong, Y. Effects of mowing regimes and climate variability on hay production of Leymus chinensis Trin. Tzvelev grassland in northern China. Rangeland J. 2014, 36, 593-600. [CrossRef]

13. Wu, N.; Liu, A.; Wang, Y.; Li, L.; Chao, L.; Liu, G. An Assessment Framework for Grassland Ecosystem Health with Consideration of Natural Succession: A Case Study in Bayinxile, China. Sustainability 2019, 11, 1096. [CrossRef]

14. Piqueray, J.; Gilliaux, V.; Decruyenaere, V.; Cornelis, J.T.; Uyttenbroeck, R.; Mahy, G. Management of Grassland-like Wildflower Strips Sown on Nutrient-rich Arable Soils: The Role of Grass Density and Mowing Regime. Environ. Manag. 2019, 63, 647-657. [CrossRef]

15. Bernhardt-Römermann, M.; Römermann, C.; Sperlich, S.; Schmidt, W. Explaining grassland biomass-the contribution of climate.; species and functional diversity depends on fertilization and mowing frequency. $J$. Appl. Ecol. 2011, 48, 1088-1097. [CrossRef]

16. Polley, H.W.; Isbell, F.I.; Wilsey, B.J. Plant functional traits improve diversity-based predictions of temporal stability of grassland productivity. Oikos 2013, 122, 1275-1282. [CrossRef]

17. Saruul, K.; Jiangwen, L.; Jianming, N.; Qing, Z.; Xuefeng, Z.; Guodong, H.; Haifeng, B. Typical steppe ecosystems maintain high stability by decreasing the connections among recovery, resistance, and variability under high grazing pressure. Sci. Total Environ. 2019, 659, 1146-1157. [CrossRef]

18. Yang, H.; Jiang, L.; Li, L.; Li, A.; Wu, M.; Wan, S. Diversity-dependent stability under mowing and nutrient addition: Evidence from a 7-year grassland experiment. Ecol. Lett. 2012, 15, 619-626. [CrossRef]

19. Leegood, R.C. Strategies for engineering C4 photosynthesis. J. Plant. Physiol. 2013, 170, 378-388. [CrossRef]

20. Brett Mattingly, W.; Hewlate, R.; Reynolds, H.L. Species evenness and invasion resistance of experimental grassland communities. Oikos 2007, 116, 1164-1170. [CrossRef]

21. Chanteloup, P.; Bonis, A. Functional diversity in root and above-ground traits in a fertile grassland shows a detrimental effect on productivity. Basic Appl. Ecol. 2013, 14, 208-216. [CrossRef]

22. Van Klink, R.; Boch, S.; Buri, P.; Rieder, N.S.; Humbert, J.Y.; Arlettaz, R. No detrimental effects of delayed mowing or uncut grass refuges on plant and bryophyte community structure and phytomass production in low-intensity hay meadows. Basic Appl. Ecol. 2017, 20, 1-9. [CrossRef]

23. Doležal, J.; Lanta, V.; Mudrák, O.; Lepš, J.; Wilson, S. Seasonality promotes grassland diversity: Interactions with mowing, fertilization and removal of dominant species. J. Ecol. 2018, 107, 203-215. [CrossRef]

24. Denelle, P.; Violle, C.; Munoz, F. Distinguishing the signatures of local environmental filtering and regional trait range limits in the study of trait-environment relationships. Oikos 2019, 128, 960-971. [CrossRef] 
25. Finegan, B.; Peña-Claros, M.; de Oliveira, A.; Ascarrunz, N.; Bret-Harte, M.S.; Carreño-Rocabado, G. Does functional trait diversity predict above-ground biomass and productivity of tropical forests? Testing three alternative hypotheses. J. Ecol. 2015, 103, 191-201. [CrossRef]

26. Ali, A.; Yan, E.R.; Chang, S.X.; Cheng, J.Y.; Liu, X.Y. Community-weighted mean of leaf traits and divergence of wood traits predict aboveground biomass in secondary subtropical forests. Sci. Total Environ. 2017, 574, 654-662. [CrossRef] [PubMed]

27. Buzzard, V.; Hulshof, C.M.; Birt, T.; Violle, C.; Enquist, B.J.; Larjavaara, M. Re-growing a tropical dry forest: Functional plant trait composition and community assembly during succession. Funct. Ecol. 2016, 30, 1006-1013. [CrossRef]

28. Zhang, Q.; Buyantuev, A.; Li, F.Y.; Jiang, L.; Niu, J.; Ding, Y. Functional dominance rather than taxonomic diversity and functional diversity mainly affects community aboveground biomass in the Inner Mongolia grassland. Ecol. Evol. 2017, 7, 1605-1615. [CrossRef] [PubMed]

29. He, Y.; Xu, M.; Qi, Y.; Dong, Y.; He, X.; Li, J.; Sun, L. Differential responses of soil microbial community to four-decade long grazing and cultivation in a semi-arid grassland. Sustainability 2017, 9, 128. [CrossRef]

30. Liang, E.; Vennetier, M.; Lin, J.; Shao, X. Relationships between tree increment, climate and above-ground biomass of grass: A case study in the typical steppe, north China. Acta Oecologica 2003, 24, 87-94. [CrossRef]

31. Wu, Z. Vegetation of China; Science Press: Beijing, China, 1980. (In Chinese)

32. Jiang, S. Setting up the experimental sites for grassland ecosystem research and vegetation status. Res. Grassland Ecosyst. 1988, 3, 1-12.

33. Olmo, M.; Lopez-Iglesias, B.; Villar, R. Drought changes the structure and elemental composition of very fine roots in seedlings of ten woody tree species. Implications for a drier climate. Plant Soil 2014, 384, 113-129. [CrossRef]

34. Connell, J.H. Diversity in tropical rain forests and coral reefs. Science 1978, 199, 1302-1310. [CrossRef]

35. Volf, M.; Redmond, C.; Albert, A.J.; Le Bagousse-Pinguet, Y.; Biella, P.; Gotzenberger, L. Effects of long and short term management on the functional structure of meadows through species turnover and intraspecific trait variability. Oecologia 2016, 180, 941-950. [CrossRef]

36. Bennett, L.T.; Judd, T.S.; Adams, M.A. Growth and nutrient content of perennial grasslands following burning in semi-arid, sub-tropical Australia. Plant. Ecol. 2003, 164, 185-199. [CrossRef]

37. Gaberščik, A.; Krek, J.L.; Zelnik, I. Habitat diversity along a hydrological gradient in a complex wetland results in high plant species diversity. Ecol. Eng. 2018, 118, 84-92. [CrossRef]

38. Adler, P.B.; Seabloom, E.W.; Borer, E.T.; Hillebrand, H.; Hautier, Y.; Hector, A.; Harpole, W.S.; O’Halloran, L.R.; Grace, J.B.; Anderson, T.M.; et al. Productivity is a poor predictor of plant species richness. Science 2011, 333, 1750-1753. [CrossRef]

39. Kemp, D.R.; Guodong, H.; Xiangyang, H.; Michalk, D.L.; Fujiang, H.; Jianping, W.; Yingjun, Z. Innovative grassland management systems for environmental and livelihood benefits. Proc. Natl. Acad. Sci. USA 2013, 110, 8369-8374. [CrossRef]

(C) 2020 by the authors. Licensee MDPI, Basel, Switzerland. This article is an open access article distributed under the terms and conditions of the Creative Commons Attribution (CC BY) license (http://creativecommons.org/licenses/by/4.0/). 